Зарубина Юлия Владимировна,

к.э.н., доцент, Ангарский государственный технический университет, e-mail: yulzar@mail.ru

АКТУАЛЬНОСТЬ ПРИОБРЕТЕНИЯ КОМПЕТЕНЦИЙ В ОБЛАСТИ ФИНАНСОВОЙ ГРАМОТНОСТИ ОБУЧАЮЩИМИСЯ ВУЗОВ

\title{
THE RELEVANCE OF COMPETENCES ACQUIRING IN THE FIELD OF FINANCIAL LITERACY TO THE STUDENTS OF UNIVERSITIES
}

\begin{abstract}
Аннотация. Рассмотрены подходы к построению успешного курса теоретической экономики с учетом возрастающей ценности компетенций в области финансовой грамотности.

Ключевые слова: финансовая грамотность, проблема выбора, дисконтирование.

Abstract. The approaches to the construction of a successful course of theoretical Economics, taking into account the increasing value of competencies in the field of financial literacy.

Keywords: financial literacy, choice, discounting.
\end{abstract}

Нынешний всплеск популярности курсов «финансовой грамотности» и вхождение их в «моду» довольно понятен и объясним в свете происходящих объективных экономических процессов. С каждым днем фринансовый мир становится все более сложным и разнообразным: в дополнение к привычным депозитам и кредитам, необходимо выбирать пенсионные фонды, располагать знаниями о возможных налоговых льготах и социальных пособиях, более того, современному человеку сегодня хорошо бы уметь принимать инвестиционные решения, ориентироваться в мире криптовалют и электронных кошельков.

В данном исследовании нам хотелось бы уделить внимание проблеме, касающейся необходимости формирования компетенций в области финансовой грамотности в современных образовательных программах и дисциплинах. Проблема современного образования в том, что зачастую выпускники ВУЗов, умеющие решать сложные профессиональные проблемы и получившие необходимые знания в своих областях, бывают бессильны перед простейшими ситуациями в обвласти управления личными финансами. Нередко принятие фринансовых решений осуществляется с ошибками, люди попадают под влияние мошенников, недостаточно ориентируются в огромном спектре предложений и условий, предлагаемых поставщиками финансовых продуктов и услуг. Финансовая сфрера у нас привычно считается закрытой для посторонних, в ней человек остается один на один со своими обстоятельствами, затруднениями, а также очень часто - с последствиями своих ошибок.

Это все делает компетенции в области фринансовой грамотности чрезвычайно важным элементом современного образования. Обучающиеся любых направлений изучают курс теоретической экономики как обязательный компонент образовательных программ, при этом содержание такого курса бывает сугубо фрундаментальным, а рассматриваемые в «стандартном» курсе теоретической экономики модели довольно плохо объясняют реальность, оторваны от нее в силу того, что в основе лежит принцип рационального 
поведения экономического субъекта, являющийся большой абстракцией. Своей практической востребованностью курс «Финансовая грамотность» выгодно отличается от «экономики классной доски», которая удобна для заполнения часов по преподаванию, но не применима для описания реального мира.

Вместе с тем, если базовых экономических знаний студенты не получили, то вряд ли преподавание курса «Финансовая грамотность» сделает их всесторонне экономически грамотными специалистами. Поэтому, необходим синтез знаний в области фринансовой грамотности и «стандартных» теоретических экономических знаний.

Моделирование успешного курса теоретической экономики предлагаем начать с выявления общих принципов экономического мышления и универсальных экономических компетенций, которые также лежат и в основе фринансово грамотного поведения.

К числу таких принципов и компетенций можно отнести:

- учет альтернативных издержек и решение проблемы выбора;

-умение использовать вычисления с помощью простых и сложных процентов;

- умение определять текущую стоимость будущих активов;

- знание характера связи риска и доходности.

Знание общей составляющей и курса теоретической экономики, и курса фринансовой грамотности позволит нам включать в темы теоретической экономики практические жизненные примеры, связанные с решением проблемы выбора, с применением приемов дисконтирования и начисления процентов.

Так, например, после теоретического изложения темы «Рыночное равновесие и его установление», опираясь на знания о конкурентных структурах и совершенной конкуренции, можно дать обучающимся практическое задание на экономический выбор. Целесообразна ли покупка нового автомобиля после нескольких лет эксплуатации старого или выгодней продолжать использовать старый автомобиль и вкладывать средства в его текущий ремонт? Можно ответить на этот вопрос, используя постулаты о конкуренции на свободном рынке и с помощью графической модели доказать, что покупка нового автомобиля, вопреки расхожему мнению, не может дать повышенной потребительской ренты.

Изучая тему «Рынок фракторов производства», можно дать расчетное задание, основанное на принципе дисконтирования, на сравнение двух вариантов инвестирования одинаковой суммы, один вариант - инвестирование в коммерческую недвижимость в некотором городе (например, в Ангарске), а второй вариант - инвестирование тех же средств в жилую недвижимость в другом городе (например, в Иркутске). Предложенный принцип синтеза в области фринансовой грамотности и «стандартных» теоретических экономических знаний позволит сделать преподаваемые курсы интересными и практически значимыми. 